Pontificla Universmade Católica

DO RIO DE JANEIRO

Epifanio Mamani Ticona

\title{
Determinação Experimental do Coeficiente de Troca de Calor em um Gerador de "Pasta de Gelo"
}

Dissertação de Mestrado

Dissertação apresentada como requisito parcial para obtenção do grau de Mestre pelo Programa de Pós-graduação em Engenharia Mecânica do Departamento da Engenharia Mecânica da PUC-Rio.

Orientador: Prof. Sergio Leal Braga

Rio de Janeiro Janeiro de 2003 
Pontificia Untversmade Católica

\title{
Epifanio Mamani Ticona
}

\section{Determinação Experimental do Coeficiente de Troca de Calor em um Gerador de "Pasta de Gelo"}

\begin{abstract}
Dissertação apresentada como requisito parcial para obtenção do grau de Mestre pelo Programa de Pós-graduação em Engenharia Mecânica do Departamento da Engenharia Mecânica do Centro Técnico Cientifico da PUC-Rio. Aprovada pela comissão Examinadora abaixo assinada.
\end{abstract}

\author{
Prof. Sergio Leal Braga \\ Orientador \\ Departamento de Engenharia Mecânica - PUC-Rio
}

Prof. José Alberto dos Reis Parise

Departamento de Engenharia Mecânica - PUC-Rio

Prof. Carlos Eduardo Reuther de Siqueira Departamento de Engenharia Mecânica - UCP

Prof. Ney Augusto Dumont Coordenador dos Programas de Pós-Graduação de Centro Técnico Cientifico PUC-Rio

Rio de Janeiro, 21 de Janeiro de 2003. 
Todos os direitos reservados. É proibida a reprodução total ou parcial do trabalho sem autorização da universidade, do autor e do orientador.

\section{Epifanio Mamani Ticona}

Graduou-se em Engenharia Eletromecânica na Escola de Engenharia Mecânica-Elétrica da Universidade Nacional de São Agustín-Perú em 1995. Atualmente tem desenvolvido um sistema de geração de Pasta de Gelo no Laboratório de Refrigeração e Aquecimento LRA dando inicio a novas pesquisas na área de sistemas de armazenamento de energia térmica com mudança de fase dinâmica e transporte de fluidos térmicos avançados.

Ficha Catalográfica

Ticona, Epifanio Mamani
Determinação experimental do
coeficiente de troca de calor em um gerador de
"pasta de gelo" / Epifanio Mamani Ticona;
orientador: Sergio Leal Braga. - Rio de Janeiro :
PUC, Departamento de Engenharia Mecânica,
2003. 107 f. : il. ; 30 cm
Dissertação (mestrado) - Pontifícia
Católica do Rio de Janeiro,
Universidade
Departamento de Engenharia Mecânica.

CDD: 621 
A Deus por tudo

Para meus pais, Bartolomé e Simona pelo imenso apoio e confiança minha gratidão é infinita e meus irmãos Wilfredo, Jaime e Patrícia. 


\section{Agradecimentos}

A meu orientador Professor Sergio Leal Braga pelo estímulo apoio e parceria para a realização deste trabalho.

Ao CNPq e à PUC-Rio, pelos auxílios concedidos, sem os quais este trabalho não poderia ter sido realizado.

Aos meus pais, pela educação, atenção e carinho de todas as horas.

Aos meus irmãos.

Aos meus amigos do LRA: José, Elizabeth, Daniel, Frank, Hugo, Rafael, Aldo além dos amigos da Reologia.

Aos meus colegas da PUC-Rio.

Ao Sr. Torben M. Hansen do DTI pelo artigo que foi de muita ajuda e esclarecedor.

Ao colega Daniel Irigon pela cessão das sub-rotinas de controle e aquisição de dados.

Aos professores que participaram da comissão examinadora.

A todos os professores e funcionários do Departamento pelos ensinamentos e pela ajuda.

A todos os amigos e familiares que de uma ou de outra forma me estimularam ou me ajudaram. 
Ticona, Epifanio Mamani; Braga, Sergio Leal. Determinação Experimental de Coeficiente de Troca de Calor em um Gerador de “Pasta de Gelo". Rio de Janeiro, de 2002. 107p. Dissertação de Mestrado Departamento de Engenharia Mecânica, Pontifícia Universidade Católica do Rio de Janeiro.

Um sistema térmico de armazenamento da energia com pasta de cristais de gelo foi desenvolvido para aplicações de condicionamento de ar e resfriamento de processos. O sistema usa um evaporador orbital de haste, um trocador de calor vertical do tipo tubo e carcaça com intensificação mecânica de transferência de calor. A pasta de gelo é produzida continuamente sem acumulação no evaporador e é compatível com unidades condensadoras convencionais, tanques de armazenamento e bombas. Soluções aquosas diluídas ou soluções inorgânicas de salmoura promovem a formação de cristais de gelo, e o gelo líquido resultante pode ser bombeado ou por gravidade alimentar um tanque de armazenamento. $\mathrm{O}$ circuito hidráulico de refrigeração (carga térmica) pode ser desacoplado da produção do gelo utilizando-se o tanque de armazenamento. $\mathrm{O}$ armazenamento de gelo líquido fornece temperaturas consistentemente baixas à medida que se derrete o gelo, que por sua forma pode ser derretido também muito rapidamente. Com suas altas temperaturas características de evaporação e elevados fluxos do calor, os sistemas de geração de gelo líquido apresentam potencial para reduzir significativamente os custos de capital inicial e operação, quando comparados com tecnologias de sistemas estáticos de gelo ou "ice harvesting".

\section{Palavras-chave}

Evaporador de película descendente, evaporador de haste orbital, Pasta de cristais de gelo, Sistemas dinâmicos de gelo liquido, armazenamento de energia térmica, armazenamento de gelo. 


\section{Abstract}

Ticona, Epifanio Mamani; Braga, Sergio Leal (Advisor). Experimental determination of the heat transfer coefficient in an ice slurry generator. Rio de Janeiro, de 2002. 107p. MSc. Dissertation - Departamento de Engenharia Mecânica, Pontifícia Universidade Católica do Rio de Janeiro.

New ice crystal slurry thermal energy storage (TES) system has been developed for both HVAC and process cooling applications. The system uses an orbital rod evaporator (ORE), a vertical shell-and-tube heat exchanger with mechanical heat transfer augmentation, as a dynamic ice maker to generate liquid ice. Ice forms continuously without accumulation in the ORE and is compatible with conventional condensing units, storage tanks, and pumps. Dilute glycol or inorganic brine solutions promote formation of ice crystals, and the resulting liquid ice may be pumped or gravity fed to a storage tank. The cooling load circuit can be hydraulically decoupled from ice production at the storage tank. Stored liquid ice provides consistently low solution supply temperatures over significant portions of the ice melt period and may be melted very rapidly. With its characteristic high evaporator temperatures and high heat fluxes, ORE TES systems have the potential for significantly lower capital and operating costs than static ice or ice harvesting technologies

\section{Palavras-chave}

Falling film evaporator, Orbital rod evaporator, Ice crystal slurry, Ice thermal storage, Thermal energy storage. 


\section{Sumário}

1 Introdução 16

$\begin{array}{ll}\text { 1.1. Tecnologia de pasta de gelo } & 17\end{array}$

1.2. Motivação 18

1.3. Vantagens do sistema de pasta de gelo 19

1.4. Classificação dos sistemas de termoacumulação 20

1.4.1. Acumuladores de calor sensível 20

1.4.2. Acumuladores de calor latente 21

1.5. Geradores de pasta de gelo 23

1.5.1. Gerador de pasta de gelo por super-resfriamento 23

1.5.2. Gerador de pasta de gelo usando raspadores 24

1.5.3. Gerador de pasta de gelo produzido por ejetor 24

1.5.4. Gerador de pasta de gelo produzido por vácuo 25

1.5.5. Gerador de película descendente agitado 26

1.6. Componentes de um sistema de refrigeração com pasta de gelo 28

$\begin{array}{ll}\text { 1.7. Conteúdo do trabalho } & 29\end{array}$

2 Análise teórica $\quad 30$

2.1. Fluidodinâmica e transferência de calor na solução aquosa 30

2.1.1. Filme fino descendente 31

2.1.2. Filme fino descendente com uma haste rotativa 37

2.1.3. Coeficiente de troca de calor 38

2.2. Fluidodinâmica e transferência de calor no fluido refrigerante $\quad 40$

2.2.1. Definições 42

2.2.2. Padrões de escoamento 43

2.2.3. Ebulição em vaso aberto (pool boiling) 44

2.2.4. Ebulição num escoamento bifásico (Flow Boiling) 45

2.2.5. Coeficiente local de Transferência de calor do fluido refrigerante 45

3 Aparato experimental 50

3.1. Solução aquosa empregada na produção da pasta de gelo 52 
3.2.1. Determinação da concentração de gelo por medição da concentração do fluido portador

3.2.2. Determinação da concentração por medição da temperatura da pasta de gelo

3.2.3. Determinação da concentração por medição das propriedades elétricas da pasta de gelo ou o fluido portador

3.2.4. Determinação da concentração por medição da massa específica 60

3.2.5. Determinação da concentração pelo método da calorimetria 65

3.3. Coeficiente de Troca de Calor

4 Procedimento experimental

5 Resultados

6 Conclusões e sugestões 83

6.1. Sugestões para trabalhos futuros

7 Referencias bibliográficas

8 Apêndice $\quad 89$

8.1. Propriedades termofisicas de soluções aquosas 89

8.1.1. Propileno Glicol 89

8.1.2. Etileno Glicol 96

8.1.3. Etanol 101

8.1.4. Propriedades de pasta de gelo com soluções aquosas de Etanol 102

8.2. Validação do método calorimétrico 105

8.2.1. Calibração do calorímetro 105 


\section{Lista de figuras}

Figura 1 - Termoacumulação de calor sensível. 20

Figura 2 - Sistema de transferência alternada "Ice on coil" 21

Figura 3 - Sistema de gelo encapsulado 21

Figura 4 - Sistemas de transferência alternada exterior 22

Figura 5 - Sistema de geração de pasta de gelo 22

Figura 6 - Produção de gelo por super-resfriamento de água 23

Figura 7 - Produção de gelo por ação de raspador. $\quad 24$

Figura 8 - Produção de gelo por ejetor 25

Figura 9 - Produção de gelo por vácuo 26

Figura 10 - Produção de gelo por película descendente agitada 27

Figura 11 - Elemento unitário de um trocador de calor de tubos 28

Figura 12 - Esquema do sistema de gerador de pasta de gelo. 28

Figura 13 - Esquema de evaporador de filme fino 31

Figura 14 - Esquema da deposição do filme 31

Figura 15 - Escoamento de filme fino descendente (a), escoamento em tubo (b) 32

Figura 16 - Espessura do filme fino descendente numa parede vertical. 34

Figura 17 - Comparação dos coeficientes de troca de calor adimensional dos escoamentos de filme fino e escoamento "cheio" 36

Figura 18 - Tecnologia de produção de gelo "Ice Harvester" 37

Figura 19 - Vista da deposição do filme de liquido na área de troca de calor 38

Figura 20 - Vista que mostra os circuitos de escoamento do fluido refrigerante e a solução aquosa $\quad 41$

Figura 21 - Padrões de escoamento, regiões de troca de calor e variação das temperaturas de parede e do fluido refrigerante 44

Figura 22 - Predição das correlações de Kandlikar, Gungor e Mattur para fluido refrigerante R22 Van P. Carey (1992) 48

Figura 23 - Variação do coeficiente de troca de calor com o titulo e fluxo de calor segundo a correlação de Kandlikar mantendo a outras propriedades constantes 49

Figura 24 - Variação do coeficiente de troca de calor com o titulo e fluxo de massa segundo a correlação de Kandlikar mantendo a outras propriedades constantes 49

Figura 25 - Diagrama de instalação do sistema gerador de pasta de gelo 50 
Figura 26 - Vista parcial do sistema gerador de pasta de gelo

Figura 27 - Amostra de pasta de gelo

Figura 28 - Variação da fração mássica do aditivo no fluido portador com a variação da fração mássica de gelo

Figura 29 - Ponto de solidificação das soluções aquosas com diferentes aditivos e variação com a concentração do aditivo em porcentagem [w/w] 56

Figura 30 - Determinação da concentração de gelo baseada na medição da concentração do fluido portadora $\quad 57$

Figura 31 - Variação da concentração de gelo por temperatura da pasta de gelo a varias concentrações inicias de etanol

Figura 32 - Determinação da concentração da pasta de gelo por medição da temperatura de solidificação

Figura 33 - Variação da massa específica de pasta de gelo de uma solução aquosa de etanol em função da temperatura e a concentração inicial em massa da solução 61

Figura 34 - Determinação da fração de gelo baseada na medição da massa específica da pasta de gelo de uma solução aquosa de etanol a diferentes concentrações 62

Figura 35 - Determinação da fração de gelo baseado na medição da massa específica da pasta de gelo de uma solução aquosa de etileno glicol a diferentes concentrações

Figura 36 - Determinação da fração de gelo baseado na medição da massa específica da pasta de gelo de uma solução aquosa de propileno glicol a diferentes concentrações

Figura 37 - Dependência da massa especifica com a concentração do aditivo na linha da temperatura do ponto de solidificação para soluções aquosas de etileno glicol

Figura 38 - Determinação da concentração de gelo pelo método de calorimetria. Incerteza na medição de temperatura $0,1^{\circ} \mathrm{C}$ Torben M. Hansen (2001)

Figura 39 - Calorímetro empregado na determinação da concentração da pasta de gelo

Figura 40 - Temperaturas do fluido refrigerante e da solução aquosa

Figura 41 - Variáveis envolvidas na temperatura de referencia $\Delta T$

Figura 42 - Vista do calorímetro empregado na determinação da fração de gelo

Figura 43 - Valores da potencia elétrica, voltagem e corrente fornecida no calorímetro ao longo do tempo

Figura 44 - Variação da temperatura da pasta de gelo durante o fornecimento de potência elétrica $\quad 74$

Figura 45 - Variação da vazão mássica durante o intervalo de coleta da amostra 74 
Figura 46 - Variação da temperatura do evaporador e o intervalo

Figura 47 - Variação da temperatura do evaporador e o intervalo 75

Figura 48 - Vista do protótipo produzindo pasta de gelo e o sensor de temperatura 76

Figura 49 - Amostra de pasta de gelo produzida pelo gerador 77

Figura 50 - A velocidade de transporte da pasta gelo deve ser considerada 78

Figura 51 - Variação da temperatura da pasta de gelo por fração de gelo 79

Figura 52 - Variação da fração de gelo versus vazão mássica e rotação da haste $\quad 80$

Figura 53 - Variação do coeficiente global de troca de calor com a vazão mássica da $\begin{array}{ll}\text { pasta de gelo } & 80\end{array}$

Figura 54 - Variação do coeficiente global de troca de calor com a velocidade da haste no evaporador $\quad 81$

Figura 55 - Variação do calor transferido na área interna de troca de calor do lado da solução aquosa 


\section{Lista de símbolos}

$\begin{array}{ll}A & \text { Área } \\ B o & \text { Numero de ebulição } \\ C & \text { Condutividade elétrica } \\ C_{\text {calorim }} & \text { Capacidade térmica do calorímetro } \\ C_{i} & \text { Constantes (i=1,2,3,4,5) } \\ C o & \text { Numero de convecção } \\ D & \text { Diâmetro interno do tubo } \\ F_{k} & \text { Constante de fluido } \\ g & \text { Aceleração da gravidade } \\ h & \text { Entalpia } \\ h_{l s} & \text { Entalpia de solidificação } \\ k & \text { Condutividade térmica } \\ K_{i} & \text { Constantes (i=1,2) } \\ m & \text { Massa } \\ \dot{m} & \text { Vazão mássica } \\ N u & \text { Numero de Nusselt } \\ \operatorname{Pr} & \text { Numero de Prandtl } \\ Q & \text { Calor trocado } \\ \operatorname{Re} & \text { Numero de Reynold } \\ t & \text { Tangencial } \\ U & \text { Coeficiente global de troca de calor } \\ v & \text { Velocidade do fluido } \\ x & \text { Concentração ou fração }\end{array}$

Letras Gregas

$\begin{array}{ll}\alpha & \text { Coeficiente de troca de calor } \\ \delta & \text { Espessura de filme } \\ \mu & \text { viscosidade dinâmica } \\ \rho & \text { Massa especifica } \\ \Gamma & \text { Vazão mássica por unidade de largura } \\ \chi_{t t} & \text { Parâmetro de Martinelli } \\ \Delta T & \text { Diferença de temperatura } \\ \Delta T_{\text {ln }} & \text { Diferença de temperatura logarítmica } \\ \Delta T_{\min } & \text { Diferença das temperaturas de saturação }\end{array}$


Subscritos

$\begin{array}{ll}a & \text { Axial } \\ \text { ad } & \text { Aditivo } \\ \text { agua } & \text { Fator } \\ \text { amost } & \text { Amostra } \\ \text { calorim } & \text { Calorímetro } \\ c p & \text { Calor específico } \\ \mathrm{f} & \text { Final } \\ \mathrm{g} & \text { Gás ou vapor } \\ \text { Geloliq } & \text { Pasta de gelo } \\ \text { Gelo } & \text { Gelo } \\ l & \text { Liquido } \\ \mathrm{L} & \text { Latente } \\ \text { lat } & \text { Lateral } \\ l s & \text { Liquido-sólido } \\ o & \text { Total } \\ \text { Ref } & \text { Fluido refrigerante } \\ S & \text { Sensível }\end{array}$

Letras Gregas

$\delta \quad$ Filme fino 
"Joy in looking and comprehending is nature's gift"

Albert Einstein 